\title{
MALIGNANT DEGENERATION IN A MATURE CYSTIC TERATOMA OF OVARY : A CASE REPORT
}

\author{
Lakhey $\mathbf{M}^{1}$, Verma $\mathrm{K}^{2}$, Khan I $\mathbf{R}^{3}$, Sah $\mathrm{S} \mathrm{P}^{4}$, Rani $\mathrm{S}^{5}$
}

\section{ABSTRACT}

\begin{abstract}
Malignant transformation of benign cystic teratoma of ovary is rare and the most common malignancy encountered is squamous cell carcinoma. The diagnosis is rarely made preoperatively and the prognosis is usually poor. Here we report a case of squamous cell carcinoma arising in a dermoid in a 44 years old lady who presented with bilateral dermoid cysts. The preoperative findings, surgical approach and adjuvant therapy are discussed.
\end{abstract}

Key Words: Malignant transformation, benign cystic teratoma, squamous cell carcinoma.

\section{INTRODUCTION}

Malignant degeneration in a mature cystic teratoma of the ovary is extremely rare, the frequency of which averages $1.4 \% .{ }^{1}$ It is rarely recognized preoperatively as most patients have symptoms, which do not differ from uncomplicated mature teratomas. The risk of malignant change is related to age and is greater in postmenopausal women. ${ }^{2}$ The most common malignant change in it is squamous cell carcinoma. A 44 years old patient with bilateral mature cystic teratoma of ovary, with squamous cell carcinoma arising in one side is being presented.

\section{CASE REPORT}

A 44 years old female patient presented to the Gynaecology Outpatient department with complaint of mass in the abdomen since 11 months. It was associated with dull aching pain. Per abdominal examination revealed a generalized asymmetric distention involving all quadrants, more towards the center, with visible stretched veins over it. Pervaginal examination revealed a uterus of normal size with a separate mass above it.

She attained menarche at 14 years of age and had regular menstrual cycles. Her last menstrual period was a month back. Despite of no use of any

1. Assistant Professor, Department of Pathology, B.P. Koirala Institute of Health Sciences, Dharan, Nepal.

2. Associate Professor, Department of Gynae. and Obst., B.P. Koirala Institute of Health Sciences, Dharan, Nepal.

3. Senior Resident, Department of Pathology, B.P. Koirala Institute of Health Sciences, Dharan, Nepal.

4. Assistant Professor, Department of Medicine, B.P. Koirala Institute of Health Sciences, Dharan, Nepal.

5. Professor and Head, Department of Pathology, B.P. Koirala Institute of Health Sciences, Dharan, Nepal.

Address for correspondence : $\quad$ Dr. Mamata Lakhey, Assitant Professor, Department of Pathology

B.P. Koirala Institute of Health Sciences, Dharan, Nepal. 
contraceptives, her only child was born 13 years after marriage.

All routine hematological and biochemical tests were within normal limits excepting for a low hemoglobin level of $8 \mathrm{gm} / \mathrm{dl}$. Ultrasonogram findings revealed bilateral ovarian dermoid cysts.

Per operative findings revealed bilateral ovarian tumour. The right ovary was replaced by a huge tumour occupying the whole abdomen. It was adherent to parts of the small intestine, ascending and transverse colon and the anterior parietal wall. Few tiny nodules were seen in the liver. The paraaortic lymphondes were not palpable. The uterus appeared normal. Total abdominal hysterectomy, bilateral salpingoophorectomy with infracolic omentectomy was performed. The right ovarian tumour ruptured accidentally while separating the adhesions.

On gross examination, the left ovarian cyst measured $6 \times 7 \mathrm{~cm}$. Cut surface was cystic, filled with pultaceous material and showed tufts of hair. The ruptured right ovarian cyst measured 16x15 $\mathrm{cm}$. The outer surface was rough and showed areas of hemorrhage and congestion. Cut surface revealed thickened solid plaques lined by necrotic tissue and tufts of hair were identified.

Microscopic examination revealed bilateral mature cystic teratomas (Fig 1). Sections from the plaques

Fig. 1, Mature cystic teratoma of ovary showing squamous epithelium and skin adnexae. (H\&E,X4) of the right ovary showed a moderately differentiated squamous cell carcinoma (Fig 2).

Fig. 2, Moderately differentiated squamous cell carcinoma arising in a mature cystic teratoma of ovary. (H\&E,X10)

Biopsy of the nodule from the surface of the liver showed metastatic squamous cell carcinoma.

\section{DISCUSSION}

Mature cystic teratomas make up almost $20 \%$ of tumours in adults, $50 \%$ of all ovarian tumours of children and bilaterality is seen in $8-15 \%$ of the cases. ${ }^{3}$ However, malignant degeneration is an extremely rare complication seen in these tumours, the risk of which increases with age. Chances of missing foci of malignant change in mature cystic teratomas is high. Hence, thorough sampling is mandatory specially from the solid areas, in the elderly and post menopausal women. Almost any component may become malignant, but squamous cell carcinoma account for $90-97 \%$ of cases followed by carcinoid tumour and adenocarcinoma. ${ }^{4,5}$ Other types include malignant melanoma, sarcoma and neuroblastoma. Out of 103 mature cystic teratomas studied in our department in the last 5 years 2 cases showed malignant change. Both were squamous cell carcinomas.

Yakushiji $\mathrm{M}$ et $\mathrm{al}^{6}$ reported 7 cases of malignant degeneration out of 145 cases $(4.8 \%)$ in a 10 years study period. In the present study the incidence is lower $(1.95 \%)$, but is compatible with the other 
reports. ${ }^{1}$ Similar findings have been reported by various other authours. ${ }^{7,8}$ Our patient was 44 years old and also showed squamous cell carcinoma. Uncommon and multiple malignancies, squamous cell carcinoma and sarcoma, ${ }^{9}$ adenosquamous and clear cell carcinoma ${ }^{10}$ arising in dermoid cysts of the ovary have been described.

Malignant change seems to be evoked by local factors as no associated multicentric tumours are found in other parts of the female genital tract, nor is there any malignant change in contralateral tumour in cases of bilateral cystic teratoma. In our case too, only the right ovarian cyst showed malignant change. In $64 \%$ of these cases the tumour extends beyond the ovary usually with adhesions to the surrounding viscera as was also evident in our case. The spread is initially local but is followed by distant metastasis. The present case also showed metastasis into the liver. The survival rate of this kind of ovarian tumours is very poor, with $27 \%$ survival after 3 years, taking into account all stages and all histological types. ${ }^{11}$ Squamous cell carcinomas seem to have a better prognosis than other histological types.

Extended surgery with wide local excision is the treatment of choice; radiotherapy and chemotherapy in advanced cases seem to yield few if any results. Our patient was planned for chemotherapy but unfortunately the patient and her relatives were unwilling, and she was discharged on request and did not turn up for follow up.

\section{REFERENCES}

1. Amerigo J, Nogales FF Jr, Fermandez - Sanz J, Oliva H, Velasco A. Squamous cell neoplasms arising from ovarian benign cystic teratoma. Gynaecologic Oncology. 1979; 8: $277-283$.

2. Gordon A, Rosenshein N, Parmeley T, Bhagavan B. Benign cystic teratomas in post menopausal women. American Journal of Obstetrics and Gyanecology. 1980; 138: $1120-1123$.
3. Prat J. In Anderson's Pathology: Female reproductive system. Damjanov I, Under J (ed) 1996 Mosby p 2293.

4 Peterson WF. Malignant degeneration of benign cystic teratomas of the ovary: a collective review of the literature. Obstet rical and Gyanecological Survey. 1967; 12: $793-830$.

5. Partoga E, Rodriguez - Ibarez T, Axtmaver RW, Noy MA, Pelegrina I. Complications of dermoid tumours of the ovary. Obstetrics and Gynaecology 1975 b; 45: $89-94$.

6. Yakushiji M, Nishida T, Sugiyama T, Mitamura T, Natsuaki Y, Nagano H, Tsunawaki A, Kato T. Malignant degeneration of benign cystic teratomas of the ovary. Acta Pathol Jpn 1981; 31: $681-688$.

7. Stamp GW, Me Connell EM. Malignancy arising in cystic ovarian teratomas. A report of 24 cases. Nippon Sanka Fuginka Gakkai Zasshi1983; 35:331 -4.

8. Chadha S, Schaberg A. Malignant transformation in benign cystic teratomas: demoids of the ovary Gan No Rinsho 1987; 33: 1860-1865.

9. Handa M, Tsujimura T, Shimizu H. Multiple malignancies (squamous cell carcinoma and sarcoma) arising in a demoid cyst of the ovary. Nippon Sanka Fujinka Gakkai Zasshi 1980; 32: $37-45$.

10. Sekiya S, Iwasawa H, Morikawa S, Takamizawa H. Malignant change of demoid cysts to the ovary. Report on an adenosquamous cell carcinoma and a clear cell carcinoma. Arch Gynecol 1984; 236: $55-59$.

11. Crouet $\mathrm{H}$, de Ranieri E, de Ranieri J. Secondary cancers arising in mature benign cystic teratomas of the ovary (dermoid cysts). Review of the literature apropos of a new case. Gan No Rinsho 1984; 30: 1840-1844. 